\title{
Análisis crítico de The Walking Dead desde la perspectiva de los valores humanistas
}

\author{
Ana Lanuza-Avello ${ }^{1}$ \\ Francisco Cabezuelo Lorenzo ${ }^{2}$ \\ Amparo García-Plaza Vegas ${ }^{3}$
}

Recibido: 2016-02-16

Enviado a pares: 2016-02-16
Aprobado por pares: 2016-03-17

Aceptado: 2016-03-29

DOI: 10.5294/pacla.2017.20.2.3

Para citar este artículo / to reference this article / para citar este artigo Lanuza-Avello, A., Cabezuelo Lorenzo, F. y García-Plaza Vegas, A. (2017). Análisis crítico de The Walking Dead desde la perspectiva de los valores humanistas. Palabra Clave, 20(2), 340-359. DOI: 10.5294/pacla.2017.20.2.3

\section{Resumen}

Este estudio se centra en el análisis de la producción audiovisual The Walking Dead para comprobar cómo esta serie de ficción utiliza distintos recursos temáticos y audiovisuales para plantear ideas que podemos relacionar con la cosmovisión y la moral cristianas. Analiza las primeras dos temporadas de la serie, ambientada en un contexto postapocalíptico, en el que un grupo de personas intenta sobrevivir en un mundo asolado por un virus que convierte a los hombres en zombis. El guion plantea diversos conflictos suscitados por esta situación entre los personajes, así como la evolución de su conciencia sobre la moralidad de sus actos.

\section{Palabras clave}

Series de televisión; postapocalipsis; The Walking Dead; zombis; cristianismo; ficción audiovisual (Fuente: Tesauro de la Unesco).

1 orcid.org/0000-0003-3380-6513. Universidad CEU San Pablo, España. ana.lanuzaavello@ceu.es

2 orcid.org/0000-0002-9380-3552. Universidad de Valladolid, España. cabezuelo@hmca.uva.es

3 Universidad Eclesiástica San Dámaso, España. agplaza@iscrsd.org 


\section{Critical Analysis of The Walking Dead from the Humanistic Values Perspective}

\section{Abstract}

This study focuses on the analysis of the audiovisual production The Walking Dead to verify how this series of fiction uses different thematic and audiovisual resources to propose ideas that we can relate to the Christian worldview and morality. It analyzes the first two seasons of the series, set in a post-apocalyptic context, in which a group of people tries to survive in a world ravaged by a virus that turns men into zombies. The script raises several conflicts raised by this situation between the characters, as well as the evolution of their conscience on the morality of their acts.

\section{Keywords}

Television series; post-apocalypse; The Walking Dead; zombies; christianity; audiovisual fiction (Source: Unesco Thesaurus). 


\section{Análise crítica de The Walking Dead a partir da perspectiva dos valores humanistas}

\section{Resumo}

Este estudo se foca na análise da produção audiovisual The Walking Dead para comprovar como esta série de ficção utiliza distintos recursos temáticos e audiovisuais para abordar ideias que podemos relacionar com a cosmovisão e a moral cristãs. Analisa as primeiras duas temporadas da série, ambientada em um contexto pós-apocalíptico, onde um grupo de pessoas tenta sobreviver em um mundo assolado por um vírus que transforma os homens em zumbis. $\mathrm{O}$ roteiro aborda diversos conflitos suscitados por esta situação entre os personagens, assim como a evolução de sua consciência sobre a moralidade de seus atos.

\section{Palavras-chave}

Séries de televisão; pós-apocalipses; The Walking Dead; zumbis; cristianismo; ficção audiovisual (Fonte: Tesauro da Unesco). 


\section{Introducción y justificación}

Gracias a las series de ficción audiovisual, la televisión vive hoy una nueva edad dorada. La creación de grandes guiones de la última década, que han permitido la aparición de series, como Mad Men (Matthew Weiner, 20072015), Breaking Bad (Vince Gilligan, 2008-2013) o Juego de Tronos (David Benioff, D. B. Weiss, 2011-hoy), junto con las nuevas posibilidades de acceso a los contenidos gracias al contexto tecnológico multipantalla, han vuelto a despertar el interés de las audiencias por las series de televisión, que se complementan y retroalimentan con cómics, relatos digitales, grupos de fanes, libros, a pesar de la crisis del sector de la comunicación acaecida en los últimos cinco años (Cabezuelo, 2013, p. 703), que ha golpeado también con mucha fuerza, sobre todo, la industria musical (López, 2014, p. 37). La industria de la comunicación enfrenta "nuevos modelos de negocio con nuevas narrativas” (Manfredi, Rojas y Herranz de la Casa, 2015, p. 265), lo cual ha provocado una "comunicación transmedia que parece que ha llegado para quedarse" (Pedreira, 2015, p. 2), que parece ser uno de los grandes "logros y desafíos de la revolución digital” (Rueda, Galán y Rubio, 2014, p. 210). Las nuevas series de televisión de éxito huyen de los grandes relatos épicos con héroes y villanos estereotipados y previsibles. Así, la posmodernidad ha supuesto "una deconstrucción de las categorías claramente establecidas y la aparición de la ambivalencia como evidencia de una visión post-metafísica del sujeto y de la identidad" (Bauman, 2005), lo cual ha dado lugar a personajes perturbadores que emergen como "héroes", cargados de traumas y más que cuestionables en el desempeño de su misión. "Una de las estrategias utilizadas por la narrativa contemporánea para acercarse a la idiosincrasia posmoderna es la conversión del protagonista en un antihéroe" (Figuero y Martínez, 2015, p. 71).

En este contexto, surge The Walking Dead (Frank Darabont, 2010hoy), producción de éxito internacional que cuenta la historia del oficial del policía Rick Grimes (Andrew Lincoln), quien, al despertar de un estado de coma, descubre que el mundo que conocía es ahora una sociedad colapsada y violenta en la que los hombres se están convirtiendo en zombis asesinos, criaturas a las que denominará "caminantes" (de ahí el título de la serie The Walking Dead, a partir de ahora abreviada en sus siglas en inglés 
$T W D$, y que podría ser traducido al español como "La muerte andante"). Tras superar un shock inicial, Rick consigue reencontrarse con su familia y se une a un grupo de supervivientes, a los que lidera para intentar sobrevivir en un desde ahora salvaje y brutal entorno.

En el primer episodio de la serie, se nos presenta a Rick Grimes (uniformado como eficiente agente del orden) explorando un espacio dantesco lleno de vehículos volcados y abandonados junto con algún cadáver ocasional. Acompañados por el desagradable zumbido de insalubres insectos, nos encontramos todo tipo de artefactos, ropa, incluso juguetes tirados, elementos carentes de sentido ante la ausencia de personas que puedan darles uso. En medio de la confusión, Rick se acerca para ayudar a una chiquilla, supuestamente asustada; pero, cuando la pequeña figura se da la vuelta, vemos que no es realmente una niña, sino un monstruo. La reacción del sorprendido Rick deja de ser la de intentar calmarla y protegerla, para pegarle un tiro en la cabeza. De este modo, antes de dar paso a la secuencia de títulos del primer episodio, el público ya tiene una inquietante pregunta a la que dar respuesta: ¿qué mundo es este donde un agente defensor de la ley y el orden se ve obligado a disparar a lo que parecería una inocente niña pequeña?

Los elementos artificiales que rodean nuestra cotidianidad pierden todo sentido cuando falta la vida humana, convirtiéndose en un montón de basura y chatarra. Pero tampoco cualquier ser que anda sobre dos pies y es capaz de recoger un juguete del suelo representa una verdadera "vida humana". El zombi es símbolo de decaimiento y corrupción precisamente de aquello que tenía vocación de ser humano. Sin embargo, las historias de zombis son todo un negocio. La industria audiovisual ha encontrado un filón en ellos y los ha convertido en los nuevos antihéroes (Castillo et al., 2016, p. 64).

La pregunta nuclear que plantea la serie ha quedado así esbozada en una de sus primeras secuencias. ¿Qué es y en qué consiste "la vida humana"? ¿Y qué ocurre si esta se corrompe y se hace inhumana? ¿Dónde se encuentra entonces la clave que da sentido a todo? En este artículo, nos planteamos como objetivo analizar la dura lucha de sus protagonistas por 
mantenerse "vivos y humanos", en el especial contexto postapocalíptico en el que se presentan, e intentar hacer una lectura de la serie desde los valores del humanismo cristiano.

\section{Metodología}

Para el análisis crítico de la serie, este trabajo atiende, en primer lugar, al estudio del contexto postapocalíptico en el que se desarrolla la acción y sus implicaciones narrativas. En segundo lugar, se centra en el análisis de los temas de fondo que se plantean y permanecen a lo largo de las dos temporadas analizadas, que se emitieron en España entre 2010 y 2013 en los canales Fox España y Neox (Grupo Atresmedia). Posteriormente, se entra en el análisis en profundidad del tratamiento de cuestiones tan relevantes, como la defensa y el sentido de la vida humana, lo cual, a su vez, desde la teoría de los imaginarios colectivos, se relaciona con la conducta de los personajes principales en la serie. El trabajo continúa la senda de otras grandes aportaciones pioneras en el estudio antropológico del fenómeno zombi en la ficción audiovisual, como las investigaciones de Jorge Martínez Lucena, publicadas en los libros de obligada referencia en la materia (2010 y 2012), pero huye de los clichés usados en ocasiones de la teoría de los estudios culturales, que "utilizan la sociología, antropología o la psicología social, para interpretar los desafíos de una sociedad cambiante, que tiene una difícil lectura desde los marcos interpretativos tradicionales" (García, 2015 , p. 97). Finalmente, es preciso subrayar que se han seleccionado para su análisis los personajes oficialmente acreditados, ${ }^{4}$ que a lo largo de estas dos temporadas presentan, bien una dimensión moral de su personalidad y un desarrollo específico de ella, bien una aparición en especial significativa. El análisis de estos parámetros nos permitirá detectar recursos narrativos y audiovisuales usados para vehicular ideas relacionadas con una cosmovisión propia del humanismo de tradición judeocristiana.

$4 \mathrm{Al}$ igual que otras series, como Lost o Falling Skies, en este caso, The Walking Dead también cuenta con un reparto de actores muy diferentes entre sí, de diferentes edades y razas y en distintas situaciones vitales, una técnica propia de series televisivas mainstreaming. Pero más allá de esto, la construcción de cada uno de los personajes en la serie está muy relacionada con el contexto apocalíptico del que hablábamos antes, que lo impulsará a formular una pregunta, cuya respuesta determinará sus acciones: ¿hay esperanza de sobrevivir? Esta pregunta no tiene aparentemente nada que ver con Dios, pero la forma en la que sea respondida puede sentar las bases para la creación de un pensamiento cristiano. 


\section{Análisis del contexto postapocalíptico}

Desde finales del siglo XX, es fácil encontrar abundante material audiovisual que atestigua el interés que despiertan las historias ambientadas en un futuro apocalíptico, en el que la civilización, tal y como la conocemos, ha desaparecido, y la especie humana es amenazada con la extinción total. El mal parece ocupar un lugar destacado en la narrativa audiovisual contemporánea, tal y como han estudiado autores, como Fuster y García-Noblejas (2011). Surgen ejemplos sugerentes en series televisivas, como La tribu (1999, Harry Duffin y Raymond Thompson), Zombis (2009, Berto Romero) o Falling Skies (2011, Robert Rodat), la serie web Electric City (2012, Tom Hanks) y, por supuesto, filmes como Exterminio (Isaac Florentine, 1999), El imperio del fuego (Rob Bowman, 2002), La guerra de los mundos (Steven Spielberg, 2005), Hijos de los hombres (Alfonso Cuarón, 2006), Soy leyenda (Francis Lawrence, 2007), La niebla (Frank Darabont, 2007), Infectados (Álex Pastor y David Pastor, 2009), La carretera (John Hillcoat, 2009), El libro de Eli (Albert Hughes, Allen Hughes, 2010), Guerra mundial Z (Marc Foster, 2013) o la española Fin (Jorge Torregrossa, 2012).

En la ficción audiovisual, la creación de un entorno es importante, porque acota y dirige la reflexión sobre la historia. El escenario determina en muchos aspectos la acción de los personajes y puede llegar a tener tanta importancia en la narrativa audiovisual como el guion o el montaje. Los contextos apocalípticos o de destrucción de la sociedad, aquellos en que el ser humano queda desprovisto de todas las ayudas que le proporciona la civilización, son en especial sugestivos a la hora de elaborar relatos que trasluzcan contenidos sobre lo que es verdaderamente importante en la vida humana, pudiendo llegar a aludir a lo trascendente, a la hora de proponer una reflexión acerca del sentido del mundo y de la vida.

La sociedad occidental contemporánea — prolongación en muchos aspectos de la estadounidense - se caracteriza por ser una sociedad individualista, donde el éxito es objeto de culto, y la soledad, el miedo a las enfermedades y las neurosis proliferan por doquier (Caerols, 2015, p. 35). La sociedad de consumo reduce a los individuos a meros consumidores en busca de lujos accesibles (Liberal y Sierra, 2013, pp. 903-930) y la tecno- 
logía parece determinar la vida de hombres y mujeres de todas las capas sociales (González-Oñate, Fanjul-Peyró y Cabezuelo-Lorenzo, 2015, p. 19).

En este contexto social real, se produce un tipo de ficción en el que la adversidad y la incertidumbre rodean a unos personajes casi siempre desconcertados y lo obliga a dar una respuesta al sufrimiento y a la desolación que existe a su alrededor. No obstante, a la hora de acercarnos a este tipo de contextos de cataclismo global, hay otros factores que deben tenerse en cuenta. En primer lugar, es necesario atender a los distintos tipos de causas que intervienen en la aparición de este tipo de escenario (meramente naturales o bien humanas, alienígenas, sobrenaturales o inexplicadas). Esas causas van a actuar como una especie de marco de coordenadas, en el que se va a desarrollar la acción de los personajes. Esto es sumamente interesante, pues, en la medida en que el origen del desastre esté relacionado con unas o con otras - con la acción del hombre o con fuerzas ajenas a su voluntad-, la reflexión al respecto podrá ser encauzada hacia el desarrollo de tesis más o menos acordes con una visión espiritual.

Los relatos en los que el origen de la catástrofe se encuentra en relación con la acción del hombre sobre la naturaleza proponen en líneas generales un tipo de reflexión acerca del lugar de la raza humana en el mundo, de su capacidad para obrar el bien, pero también del peligro que entraña para el hombre jugar a ser Dios. Si bien nos encontramos ante un razonamiento que insinúa la existencia de un creador o, al menos, un demiurgo, estos relatos pueden limitarse a ofrecer visiones fundamentalmente inmanentes, reflexiones sobre el hombre o la vida que tienen más que ver con la responsabilidad que con la trascendencia.

También comprobamos cómo el contexto apocalíptico facilita la construcción de personajes, que se ven obligados a plantearse con radicalidad el sentido de su supervivencia, incluso la existencia de Dios. Es el caso de Soy leyenda (Francis Lawrence, 2007), película en la que la doctora Alice Krippin (Emma Thompson) en su intento de encontrar una vacuna contra el cáncer crea un virus que transforma a los humanos en zombis. El protagonista, Robert Neville (Will Smith), había llegado a creer que era el último 
habitante del planeta, pero, finalmente, termina sacrificando su vida por salvar a otros hombres y mujeres, con la convicción de que este supremo sacrificio responde al plan de Dios para él. ${ }^{5}$

La situación apocalíptica puede provenir también de la propia naturaleza que se rebela o que simplemente muestra al hombre su poder de destrucción. Este discurso está fundamentalmente relacionado con una reflexión sobre el ecologismo y, aunque también se suele desarrollar en un contexto de destrucción que nos ofrece la posibilidad de tratar temas cercanos al sentido de la existencia humana, puede seguir situándonos en un entorno fundamentalmente inmanente. En esta línea, encontramos películas, como El incidente (2008), del director de origen indio M. Night Shyamalan. Según sostiene el profesor e investigador Antonio Sánchez Escalonilla (2012, p. 12) en El incidente sobre Shyamalan, este director:

Sigue el patrón amenaza-catástrofe-supervivencia bajo la sombra de la agresión terrorista, pues la toxina liberada por las plantas recuerda la psicosis del ataque con ántrax tras el 11-S. Sin embargo, el planteamiento se invierte cuando se comprueba que los propios hombres son "una amenaza para este planeta [...] Más allá de las explicaciones científicas 0 ecológicas del argumento, el director emplea el patrón de la catástrofe para explorar las reacciones humanas y sociales ante la agresión, así como los efectos traumáticos provocados en los personajes de El incidente, Elliot y Alma en especial.

Pero ¿cuáles son las causas de la catástrofe en TWD? En la serie aquí analizada, el origen del mal que convierte a los hombres en zombis no es conocido. Parece provenir de un virus o una bacteria, tal como explica el doctor Edwin Jenner (Noah Emmerich) en el capítulo TS-19 (primera temporada). El doctor Jenner es un investigador que ha experimentado con el cerebro de su propia mujer, quien se prestó a ser objeto de observación mientras se convertía en un zombi. Debido a un accidente, los experimentos que Jenner había llevado a cabo se destruyen y, con ellos, la posibilidad de saber si hay o no una explicación científica. No hay que olvidar que la

5 La primera gran película de zombis, titulada Night of the Living Dead (La noche de los muertos vivientes), de 1968, dirigida por George A. Romero, se inspira en la novela I am Legend (Soy Leyenda), del escritor Richard Matheson de 1954 . 
ciencia y la tecnología han sido consideradas por muchos como la esencia de las sociedades occidentales desarrolladas, como la europea (Sotelo González, 2012, p. 122), frente a paraísos orientales o países en vías de desarrollo. Este episodio cierra la primera temporada planteando la cuestión desde un particular punto de vista, el de un científico que ha perdido toda esperanza.

\section{El sentido de la vida en una sociedad destruida}

En el episodio final de la primera temporada, TS-19, el doctor Jenner deja traslucir su convicción de que los seres humanos no somos otra cosa que la actividad de nuestras sinapsis cerebrales. Cuando el cerebro muere, no queda nada de la persona, lo que surge después, una vez que la infección reinicia el funcionamiento de la parte más básica del cerebro, son solo funciones instintivas, que no tienen nada que ver con la corteza cerebral que contenía las memorias, los sentimientos o los pensamientos humanos.

Esta visión materialista de la vida humana es la que está detrás de la impresionante afirmación que hace este científico de que la mayoría de sus compañeros científicos de otros laboratorios del mundo se han suicidado al darse cuenta de que no había ningún remedio. La razón para vivir de aquellos que aguantaron más tiempo fue la de encontrar una solución a la enfermedad (o en su caso, por la promesa que le hizo a su esposa de aguantar mientras pudiera); pero, en su concepción de las cosas, ya nada tiene sentido. Andrea (Laurie Holden) repite que "todo se ha terminado", "no queda nada”. A este respecto, el profesor Jorge Martínez Lucena (2010, p. 78) sostiene que en TWD:

Se presta especial atención a estos humanos que todavía no se han convertido. No solo encontramos en ella [en la serie] la novedad de que los que mueren por causas naturales o por mero accidente también se convierten en zombis (se hace imposible morir y descansar normalmente). También vemos cómo la trama del relato se centra mucho más en los efectos psicológicos que la conciencia post-apocalíptica tienen [sic] sobre los supervivientes. En este nuevo mundo en que la epidemia de la muerte avanza ineluctablemente, los diferentes personajes se sorprenden entregados a una soledad que muy difícilmente no desembocará en la más radical desesperación. 
Jenner ha aceptado morir cuando se produzca la autodestrucción de las instalaciones del Centro para el Control y la Prevención de las Enfermedades de la Administración estadounidense, sencillamente el sistema no lo deja salir, pero él tampoco lo intenta. Jacqui (Jeryl Prescott) quiere hacer lo mismo, pues, le parece realmente lo más razonable, lo más "cuerdo". Sin embargo, la mayor parte del grupo no se resigna a esa muerte. Parecerán locos ante la perspectiva (fracasada) de los científicos, pero ellos aún quieren salir e intentar sobrevivir, quieren tener al menos la oportunidad de encontrar algo por lo que merezca la pena tanto sufrimiento. Esta es la respuesta vital, visceral, que nos ofrece TWD ante el nihilismo de Jenner. Ante la obligación forzada a tener que decidir en cuestión de minutos si quieren vivir en una situación apocalíptica o morir sin dolor, estas personas optan por vivir, aun cuando no quede nada, apostando porque también la vida en sí, sin nada más, tiene algún sentido.

El origen del mal quedará en el misterio, pero tampoco importa verdaderamente. En este contexto, el doctor Jenner sugiere que el origen del mal "podría ser un microbio, virus u hongo", a lo que Jacqui le contesta que quizá el origen sea "la ira de Dios". Sin embargo, el médico, en un intento de acallar a Jacqui, le responde evasivamente, como queriendo conceder esa posibilidad, aunque no tenga para él mucho significado, ya que una posible creencia en Dios no desempeña ningún papel en sus decisiones. De este modo, es la situación de extrema carencia y enorme y continuado peligro la que impulsará a los personajes y al espectador —en la medida en que se identifica con ellos- a plantearse las preguntas fundamentales sobre la vida. Pero la respuesta a estas preguntas queda abierta, y solo algunos personajes acudirán a Dios para responderlas.

No obstante, este ya no será meramente un creador o demiurgo, una causa última del universo, sino un Dios personal, que podrá ser interpelado, como de hecho ocurre en algunos de los episodios en los que los personajes adoptan actitudes propias de un creyente, pero que no surgen de una fe madura y consiente, sino de un cierto resquicio de fe heredada al que se acude como último recurso ante la experiencia puramente vital, corpórea, sensitiva, de su propio sufrimiento. Así, en el episodio titulado What 
Lies Ahead (segunda temporada), Rick reza ante un crucifijo, encontrado en una iglesia que les ha llamado la atención por su toque automatizado de campanas, pidiendo ser iluminado a la hora de tomar decisiones. Su oración no es la de un hombre que cree profundamente en los designios divinos, sino la de alguien desesperado que le grita a Dios para que le ayude a tomar las decisiones adecuadas. Rick pide una señal al cielo:

\begin{abstract}
No sé si me estás mirando con... ¿tristeza, desprecio, compasión, amor? Tal vez solo indiferencia. Imagino que ya sabes que no soy muy creyente. Supongo que decidí para poner mi fe en otra parte: mi familia, sobre todo, mis amigos, mi trabajo... Lo que pasa es que nosotros... yo... nos vendría bien un poco de algo que nos ayudara a seguir adelante. Algún tipo de reconocimiento, alguna indicación que me corrobore que estoy haciendo lo correcto. Nos sabes lo difícil que es conocer, o quizá sí. Oye, mira, yo no necesito todas las respuestas. ¡Solo un pequeño empujón 0 una señal! ¡Cualquier signo servirá! 6
\end{abstract}

Las dudas espirituales de Rick y su petición, casi exigencia, de un signo divino son un ejemplo más de los contenidos dignos de análisis para una lectura crítica de la serie. A esta cuestión se suma el problema de cómo interpretar estas posibles señales, lo cual tiene que ver en especial con la ética y estética.

\title{
El contraste entre la destrucción total y la verdad, la bondad y la belleza
}

Las emociones asociadas a lo estético llamaron la atención de la filosofía desde el principio de los tiempos (Zumalde, 2011). En la ficción audiovisual, la puesta en escena resulta un elemento primordial a la hora de trasladarnos a un determinado ambiente. Los paisajes, los edificios, los decorados, la elección y la disposición de los objetos o los efectos especiales, junto con la actuación de los protagonistas, encierran una potencialidad narrativa indiscutible. En la serie que nos ocupa, a lo largo de las dos primeras temporadas, sobresalen paisajes en los que queda patente la destrucción

6 "I don't know if you're looking at me with what... Sadness, scorn, pity, love? Maybe just indifference. I guess you already know I'm not much of a believer. I guess I just chose to put my faith elsewhere; my family, mostly, my friends, my job... The thing is, we... I... could use a little something to help keep us going. Some kind of acknowledgment, some indication I'm doing the right thing. You don't know how hard it is to know, or maybe you do. Hey look, I don't need all the answers. Just a little nudge or sign! Any sign will do!”. 
de una cultura y un modo de vida propiamente humanos. La naturaleza no es invadida por el mal que asola el planeta, solo los seres humanos son víctimas. Así, la visión de grandes ciudades desiertas y destruidas se erige como un potente símbolo de la fragilidad humana, impactante imagen de destrucción ante la que el hombre también va a reclamar una respuesta. El contexto de destrucción en el que se mueven los personajes permite crear un contraste interesante entre la devastación del entorno y todo lo bueno que aún existe en él. La experiencia de verdad, de bondad y de belleza deja una huella profunda en algunos de los personajes, y les ayuda a conformar su visión del mundo y a renovar su esperanza.

Ante la conmoción sufrida, el mundo se tambalea y a los personajes les urge buscar certezas que les impulsen a seguir. A este respecto, resulta significativa la conversación entre Rick y Lorie (Sarah Wayne Callies) en el capítulo Wildfire (primera temporada), en el que Lorie le pregunta a su marido si está seguro de algo, a lo que Rick responde que está seguro de que la quiere. ${ }^{7}$ Desde el principio de la serie, el protagonista actúa movido por una experiencia de compasión. Antes de su ingreso en el hospital, Rick era un hombre perdido en muchos aspectos, pero, a partir de la experiencia de ser ayudado y acogido por Norman (Lennie James) y su hijo Duane (Adrian Kali Turner), adquiere una deuda con su prójimo y se convierte en una fuerza de valor y esperanza.

Otro ejemplo podría ser el de Daryl Dixon, interpretado por Norman Reedus. Su incondicionalidad respecto de Sophia (Madison Lintz) y su empeño por encontrarla impulsan a Carol, la madre de la niña (Melissa McBride), a decirle que él es bueno, tan bueno como Rick o Shane, "incluso más". El propio Daryl lucha contra su propia tendencia a la brutalidad, estrechamente vinculada a la relación con su hermano, quien se le aparece como un fantasma y a quien significativamente pide que se vaya, porque "estaba mejor sin él”. Y, por último, está el caso de Jim (Andrew Rothenberg), que es atacado por un zombi y pide a sus compañeros que lo abandonen en el camino, pues, si permaneciese con ellos, sería un lastre. Estos gestos de los personajes, así como la forma en la que el resto los reciben, hacen que

7 Lorie: “Tell me something with certainty”. Rick: "I love you. That's... that's all I got”. 
la solidaridad, la generosidad, la defensa de la vida o el sacrificio por los demás aparezcan como actitudes y valores objetivamente buenos y deseables.

Finalmente, y con una relación directa con una puesta en escena en la que existe un impactante contraste entre la destrucción de la civilización humana y la naturaleza intacta, se encuentra la experiencia de belleza, una de las que influyen en Rick de manera más evidente. En el capítulo titulado Bloodletting (segunda temporada), en una de las incursiones en las que salen a buscar a Sophia, Rick, Shane (Jon Bernthal) y Carl (Chandler Riggs) ven un ciervo. Carl se acerca sigilosamente al animal, que no se mueve, y lo mira fijamente. De repente, se oye un tiro dirigido al ciervo que por error alcanza al niño, el cual queda malherido. Cuando Carl se despierta gravemente herido, lo primero que hace es hablar de la belleza del animal, actitud que impacta a su padre, que esperaba que su hijo se asustara de su propio estado o de su dolor. Pero lejos de esto, Carl relata con emoción la impresión que le causó ver una criatura tan imponente sosteniendo su mirada, y esto conmueve profundamente a Rick, quien se da cuenta de que la belleza tiene un poder sobre el hombre, aún mayor que la destrucción o el dolor. El personaje de Carl plantea la pregunta por la educación moral de los niños en un ambiente de extrema dureza y crueldad. Para Serradilla (2011, p. 24), el oficial de policía Rick Grimes y su hijo Carl conforman una suerte de guía teórico-práctica en cuanto a los problemas que un padre y un hijo deben sortear, a medida que ambos van creciendo juntos, independiente de que dicha relación se desarrolle en un mundo en ruinas e invadido por zombis.

\section{La defensa y sentido de la vida como temas de fondo de TWD}

El género de la ficción ofrece infinitas posibilidades de crear paralelismos entre las tramas seriales y cuestiones de gran calado que atañen al hombre actual. En nuestro caso, podríamos hablar no solo de la capacidad de dar sentido al propio sufrimiento, sino también de las ancestrales cuestiones morales sobre la vida (suicidio, pena de muerte, eutanasia, aborto...), que se plantean con solidez en estas dos temporadas. El guion de la serie que nos ocupa nos sitúa frente a una pregunta, cuya respuesta está estrechamen- 
te vinculada a la defensa de la vida: ¿cuándo la vida de los hombres deja de llamarse vida humana?

A lo largo de la serie, son varios los momentos en los que esta cuestión se pone de manifiesto. El primero de ellos plantea la cuestión de forma simbólica: ¿son los zombis seres humanos? El granjero Hershel Grenne (Scott Wilson) se niega a verlos como formas de vida no humanas, y su creencia de que los zombis no son más que hombres y mujeres enfermos lo impulsa a custodiarlos en un granero cerca de su hogar.

En el contexto de crisis e incertidumbre que plantea la serie, los personajes deben tomar una decisión: optar por la esperanza e intentar luchar y sobrevivir en medio del horror, o rendirse ante la que creen una evidencia: el final de su existencia como seres humanos. Todos los personajes han de elegir, y esa elección lo guiará en su camino y explicará cada una de sus acciones, acciones que han de tener, o no, algún sentido. La siguiente pregunta queda entonces planteada: ¿por qué seguir luchando en este contexto de ruina y desesperación? ¿Hay o no lugar para la esperanza en este mundo?

Todos los personajes tienen depositada su esperanza en algo o aman a alguien. Rick espera poder guiar al grupo y a su familia, Shane estar con Lorie y Carl (la mujer y el hijo de Rick), el doctor Edwin Jenner en encontrar una cura para los zombis, Andrea quiere a su hermana y Dale (Jeffrey DeMunn) quiere a Andrea. La mayoría de los personajes tienen una visión intrascendente de su propia existencia, lo cual provoca que, cuando estas esperanzas se manifiestan como vanas, o el sujeto amado desaparece, desaparezca también el sentido de sus vidas. Sin embargo, otros personajes, como Morgan, Rick, Dale o Hershel, proponen visiones que trascienden esta visión limitada y entienden que es necesario luchar por algo más que ellos mismos. Todos ellos comparten un concepto del bien común, que los sitúa como líderes o como fuerzas de bien que animan al grupo a continuar.

El mayor desafío al que se enfrentan los personajes es encontrar un por qué a su dolor. Al extirpar las razones de tipo espiritual, algunos personajes se encuentran sin respuestas satisfactorias ante el drama del sufri- 
miento, y el suicidio se convierte en una actitud coherente ante la falta de esperanza y la negación de la trascendencia. Resulta lógico, por tanto, que el doctor Jenner, Jacqui y Andrea decidan quedarse en el Centro de Control de Epidemias y morir de una manera rápida e indolora. ${ }^{8}$

Pero la rendición puede adoptar muchas formas, no siempre tiene que ver con el suicidio, sino también con el asesinato o el ejercicio de la extrema crueldad. En el caso de Lorie, su inicial falta de esperanza en un futuro mejor la impulsa a plantearse abortar al enterarse de que está embarazada. No obstante, estamos ante un personaje atormentado, cuyos principios irán evolucionando a medida que avanza la serie para acercarse progresivamente a una visión de la situación más esperanzada y generadora, por tanto, de una actitud animosa y luchadora.

Rick y Shane ejemplifican dos formas de enfrentarse a la realidad. Ambos son líderes y amigos. Sin embargo, hay algo que los diferencia radicalmente: la capacidad para trascender su propio deseo y luchar por el bien de su comunidad. Rick actúa de acuerdo con una ética, pues, es capaz de trascender su realidad más inmediata y reconocer la dignidad que comparten todos los seres humanos. Por eso, a partir de una experiencia de bondad y generosidad incondicional, en el momento en el que Norman lo acoge y cuida de él en su casa, ${ }^{9}$ se convierte en un hombre que cree que hay que luchar por todos y cada uno de los hombres y las mujeres que lo rodean y en los que reconoce a su prójimo. Rick quiere proteger a su familia, pero sospecha que ese no es el último fin de su vida, no es algo en lo que pueda depositar su fe. Cada día, su esperanza se recompone a partir de pequeñas experiencias de verdad, bondad y belleza, a las que es sensible y de las que

8 No obstante, junto con este tipo de personajes, podemos encontrar otros, que, si bien deciden optar por el suicidio, tienen conciencia de que hacerlo es pecado. Así ocurre con una pareja de ancianos, que, antes de quitarse la vida en su casa, escriben en la pared "Dios, perdónanos" (God forgive us), en el episodio Days Gone Bye (primera temporada). La introducción de estos elementos de puesta en escena enriquece el guion de la serie al aportar puntos de vista diversos acerca de la legitimidad del suicidio en una situación tan extrema como la que plantea la serie que nos ocupa.

9 En el capítulo "Tell it to the Frogs" (primera temporada), el protagonista Rick justifica ante su mujer Lorie su decisión de volver a Atlanta con la deuda moral adquirida con Norman. "Tengo una deuda con un hombre al que conocí y su hijo. Lorie, si ellos no me hubieran rescatado, ahora estaría muerto" (I owe a debt to a man I met and his little boy. Lorie, if they hadn't taken me I'd have died"). 
saca fuerzas para guiar al grupo. La lucha de Rick por cada hombre se convierte en la lucha por la humanidad.

El personaje de Shane, sin embargo, tiene un horizonte más limitado, pues la fuerza que lo mueve es egoísta. Está enamorado de Lorie, con quien mantuvo relaciones cuando esta pensaba que su marido estaba muerto. Shane es un personaje narcisista, que solo aparentemente vela por la seguridad de todos. Su esperanza tan solo consiste en estar con Lorie, y por este deseo es capaz de sacrificar todo. Por tal motivo, el propio personaje se convierte en una fuerza de destrucción. Resulta interesante comprobar cómo a medida que se suceden los capítulos la esperanza de Rick aumenta y su matrimonio se fortalece, mientras que la desesperación y el descontrol crecen en Shane. Cada personaje parece estar recibiendo, desde el comienzo de la serie, una justa recompensa por su actitud, hecho a través del cual se consigue que el espectador identifique la actitud de Rick como la adecuada. Shane parece ser redimido por su propio remordimiento y la posibilidad cada vez más lejana de conseguir a Lorie.

\section{Conclusiones}

Sin duda alguna, la serie TWD ofrece un interesantísimo material de análisis de la conducta humana en un contexto marcado por la desesperación y la falta de respuestas, susceptible de ser analizado tanto desde una perspectiva ética como estética, en función de si atendemos a los ejes temáticos que presenta o a los recursos audiovisuales que utiliza para vehicular dichos temas. A este respecto, podemos afirmar que el guion de la serie destila una ausencia de cinismo en el planteamiento de la que carecen otras series televisivas de culto, como Dexter (James Manos Jr., 2006-2013), producción estadounidense de gran éxito que comparte con TWD una puesta en escena decididamente gore (sangrienta) que se constituye como una defensa del relativismo moral. Sin embargo, en $T W D$, el valor de la vida humana se afirma con rotundidad desde el comienzo. El guion no deja lugar a dudas: aquel para quien el valor de la vida es algo relativo se convierte en un factor de destrucción. Como resultado del análisis de las dos primeras temporadas de esta serie de éxito mundial, el mejor ejemplo de tal afirmación se encuentra en el estudio del personaje de Shane, para quien la supervi- 
vencia y la defensa de aquellos a quienes desea proteger justifican cualquier decisión sobre quién debe vivir o morir, al margen de otras consideraciones, como los vínculos afectivos y familiares de aquellos a quienes ama o la defensa del bien común. De entre los personajes que en las dos primeras temporadas luchan por su supervivencia, tanto en el caso del protagonista Rick Grimes como de su mujer Lorie, es preciso subrayar que, desde la perspectiva del humanismo cristiano, los dos son buenos ejemplos de personajes que luchan por encontrar respuestas adecuadas en el nuevo contexto, presentando una dimensión moral irrenunciable. Por otro lado, encontramos personajes, como Morgan, Dale o Hershel, que presentan sólidos rasgos morales o religiosos. En el caso de Daryl, este sufre una indudable evolución hacia un mayor sentido moral. Por otro lado, Shane y Merle están dispuestos a dejar atrás toda moral para sobrevivir. Finalmente, los personajes de Jacqui, el doctor Jenner y Andrea representan lo contario, ya que se rinden por completo, y eligen morir de una manera rápida e indolora antes de seguir luchando.

\section{Referencias}

Bauman, Z. (2005). Modernidad y ambivalencia. Barcelona: Anthropos.

Cabezuelo Lorenzo, F. (2013). Cinco años de crisis en el mercado de la comunicación (2008-2013). Revista Historia y Comunicación Social, $18(3), 703-715$.

Caerols Mateo, R. (2015). Mitos de la creatividad, el genio y la locura a través de la obra de Woody Allen. Doxa Comunicación, 20, 33-64.

Castillo, D. et al. (2016). Zombie Talk: Culture, History and Politics. Palgrave Macmillan: Nueva York.

Figuero Espadas, J. y Martínez Lucena, J. (2015). To all law enforcement entities, this is not an admission of guilt. Antiheroísmo y redención en "Breaking Bad”. Revista Comunicación y Hombre, 11, 69-81. 
Fuster, E. y García-Noblejas, J. J. (2011). Repensar la ficción. El mal moral en las pantallas: necesidades dramáticas y patologías industriales. EDUSC: Roma.

García López, J. (2015). Publicidad, comunicación y cultura. Barcelona: Editorial UOC.

González-Oñate, C., Fanjul-Peyró, C. y Cabezuelo-Lorenzo, F. (2015). Uso, consumo y conocimiento de las nuevas tecnologías en personas mayores en Francia, el Reino Unido y España. Comunicar: Revista Científica Iberoamericana de Comunicación y Educación, 45, 19-28.

Liberal Ormaechea, S. y Sierra Sánchez, J. (2013). Los atributos definitorios de una marca de lujo para los consumidores. Intangible Capital, 9(3), 903-930.

López Medel, I. (2014). La muerte y la resurrección de la portada de discos. Index Comunicación, 4(1), 37-58.

Manfredi Sánchez, J. L., Rojas Torrijos, J. L. y Herranz de la Casa, J. M. (2015). Innovación en el periodismo deportivo: modelo de negocio y narrativas. El Profesional de la Información, 24(3), 265-273.

Martínez Lucena, J. (2012). Ensayo Z: antropología de la carne perecedera. Berenice: Córdoba.

Martínez Lucena, J. (2010). Vampiros y zombis posmodernos, la revolución de los hijos de la muerte. Gedisa: Barcelona.

Pedreira Souto, E. (2015). Comunicación transmedia y nuevas narrativas. Revista Comunicación y Hombre, 11, 17-18.

Rueda Laffond, J. C., Galán Fajardo, E. y Rubio Moraga, Á. L. (2014). Historia de los medios de comunicación. Madrid: Alianza. 
Sánchez Escalonilla, A. (2012). Incomunicación y trauma en el cine de M. Night Shyamalan. FilmHistoria, 22(1), 12.

Serradilla, E. (2011). Robert Kikman: de The Walking Dead a Invencible. Palma de Mallorca: Dolmen.

Sotelo González, J. (2012). La peculiaridad esencial de la cultura europea: la ciencia y la técnica moderna. Revista de Occidente, 376, 122-141.

Zumalde Arregi, I. (2011). La experiencia filmica: cine, pensamiento y emoción. Madrid: Cátedra. 